\title{
A DIMENSÃo dA QUALIDADE DE ÁGUA: AVALIAÇÃo DA RELAÇÃO ENTRE INDICADORES SOCIAIS, DE DISPONIBILIDADE HídRICA, DE SANEAMENTO E DE SAÚdE PÚBLICA
}

\author{
THE WATER QUALITY DIMENSION: AN EVALUATION OF THE RELATIONSHIP \\ BETWEEN SOCIAL, WATER AVAILABILITY, WATER SERVICES AND \\ PUBLIC HEALTH INDICATORS
}

\section{Paulo Augusto CunHa LibÂNio}

Especialista em Recursos Hídricos da Agência Nacional de Águas (ANA). Engenheiro Civil (UFMG, 1999). Mestre em Engenharia Sanitária e Ambiental (UFMG, 2002). Doutorando do Programa de Pós-Graduação em Saneamento,

Meio Ambiente e Recursos Hídricos (DESA/UFMG)

\section{Carlos Augusto de Lemos Chernicharo}

Professor Adjunto do Departamento de Engenharia Sanitária e Ambiental da UFMG. Engenheiro Civil e Sanitarista. Doutor em Engenharia Ambiental pela Universidade de Newcastle upon Tyne - UK

\section{NILO DE OLIVEIRA NASCIMENTO}

Professor Adjunto do Departamento de Engenharia Hidráulica e Recursos Hídricos da Escola de Engenharia da UFMG.

Engenheiro Civil pela UFMG. Mestre em Hidrologia pela École Polytechnique Fédérale de Lausanne, Suiça. Mestre e Doutor em Recursos Hídricos pela École Nationale des Ponts et Chaussées, França

Recebido: 21/10/04 Aceito: 28/06/05

\section{RESUMO}

O processo de implementação do novo modelo brasileiro de gestão de águas, instituído em âmbito nacional pela Lei 9.433/97, somente poderá ser avaliado positivamente se resultar em avanços nas questôes relativas à qualidade das águas naturais. Assim, ganham especial importância as demandas específicas dos setores ambiental e de saneamento, as quais não podem mais ser negligenciadas no planejamento do aproveitamento hídrico. O presente trabalho buscou, a partir da comparação da relação de indicadores de disponibilidade hídrica e de saneamento com indicadores sociais e de saúde, destacar a importância da dimensão da qualidade de água na gestão dos recursos hídricos. Constatou-se que a condição de vida das populaçôes é melhor retratada pela abrangência dos serviços de água e esgoto do que pela reservas hídricas medidas em termos meramente quantitativos.

PALAVRAS-CHAVE: Recursos hídricos, qualidade de água, saneamento, saúde pública, indicadores.

\begin{abstract}
The implementation of Brazil's new national water resources management system (Law 9.433/97) may be positively evaluated only if it promotes advances in water quality issues. Hence, environmental sectors and water services demands gain importance and no longer can be neglected in water resources planning. This paper was aimed at highlighting the importance of water quality in water resources management, as noted from the comparison of water availability, water services, social and public health indicators. It was observed that living conditions is better described by water supply and sanitation coverage than by water reserves measured quantitatively.
\end{abstract}

KEYWORDS: Water resources, water quality, water services, public health, indicators.

\section{INTRODUÇÃO}

A gestão de recursos hídricos no Brasil esteve por longo tempo reduzida à avaliação quantitativa das reservas hídricas, especialmente para fins de produção de energia, resultado do modelo de gestão centralizado então em vigor, basicamente voltado às necessidades de planejamento estratégico do setor de hidroeletricidade (Muñoz, 2000).

Nesse período, os setores usuários de recursos hídricos mais dependentes da qualidade de água, incluindo-se o setor de saneamento, ficaram praticamente ausentes do processo decisório sobre o aproveitamento hídrico no nível sistêmico das bacias hidrográficas, realizando ou proje- tando seus investimentos de forma pontual e desarticulada.

Esse quadro começou se alterar a partir das reformas políticas transcorridas ao longo do processo de redemocratização do país, as quais revigoraram a participação da sociedade civil organizada e criaram novos canais de comunicação institucional, estimulando novas formas 
de mobilização e de representação social. Especificamente para o setor hídrico, essas transformações produziram importantes efeitos, surgindo em alguns estados, experiências de gestão de água inovadoras.

As leis estaduais de recursos hídricos editadas a partir do início da década de 1990 e, posteriormente, a Política Nacional de Recursos Hídricos (PNRH), instituída pela Lei $9.433 / 97$, ao incorporarem o princípio do aproveitamento múltiplo e integrado dos recursos hídricos, afirmaram a opção brasileira por um modelo de gestão de águas que contemplasse simultaneamente aspectos quantitativos e qualitativos.

Nessa nova perspectiva de gestão dos recursos hídricos, ganham importância as questôes situadas na interface entre as áreas de recursos hídricos e de saneamento ambiental. Entre essas questôes, destacam-se algumas de caráter mais abrangente, como as intervençôes voltadas ao controle da poluição hídrica difusa - por exemplo, drenagem e disposição de resíduos sólidos - e outras mais específicas, por sua estreita e direta relação com a saúde pública, caso dos serviços públicos de abastecimento de água e de esgotamento sanitário.

A contaminação das águas naturais representa um dos principais riscos à saúde pública, sendo amplamente conhecida a estreita relação entre a qualidade de água e inúmeras enfermidades que acometem as populações, especialmente aquelas não atendidas por serviços de saneamento.

A relação de causalidade entre as condiçôes de saneamento e de meio ambiente e o quadro epidemiológico é reconhecida pelos legisladores brasileiros que, por exemplo, na Lei 8.080/90 - que dispõe sobre a prestação dos serviços de saúde no País - citam tais condiçôes como alguns dos fatores determinantes para a saúde pública $\left(\operatorname{art} .3^{\circ}\right)$.

A Figura 1 ilustra a vasta interface do conjunto "saneamento ambiental" e sua importante dimensão junto à gestão de recursos hídricos e à saúde pública.

O presente artigo objetiva demonstrar que a disponibilidade hídrica é condição importante mas não suficiente para garantir o bem-estar social, o qual pode ser melhor apreendido pelo alcance de serviços essenciais para a população, tais como os serviços de abastecimento de água e de esgotamento sanitário.

Nesse sentido, considerando-se informações de estudos de âmbito nacional e internacional, investigou-se a hipótese de que, em muitas situaçôes, os indicadores de saneamento - particularmente, nesse estudo, a abrangência dos serviços de água e esgoto-apresentam melhor correlação com os indicadores que expressam as condiçôes de vida das populaçôes: indicadores de desenvolvimento social - IDH e expectativa de vida - e de saúde pública - índice de mortalidade e morbidade por doenças parasitárias e infecciosas de veiculação hídrica.

\section{METODOLOGIA}

\section{Período de tempo de referência dos estudos consultados}

Todos os dados secundários utilizados no presente estudo referem-se ao ano de 2000, período da última pesquisa censitária do IBGE que aferiu a cobertura dos serviços de água e esgoto nas unidades da Federação. Tal cuidado foi necessário haja vista o interesse do trabalho em avaliar as correlaçôes entre os indicadores de saneamento com os demais, aproximando-se a base de comparação.

Assim, ainda que tenham sido divulgadas informações mais recentes sobre as demais variáveis contempladas no estudo - por exemplo, o Índice de Desenvolvimento Humano (IDH) em 2002 para os países pesquisados pelo Programa das Nações Unidas para o Desenvolvimento (UNDP, 2004) - a análise das mesmas deteve-se às informaçōes do ano de 2000 .

\section{Indicadores sociais: Índice de Desenvolvimento Humano (IDH) e expectativa de vida}

Atualmente é amplamente reconhecido que a condição de vida das populações não pode ser retratada exclusivamente pela dimensão econômica. Tal

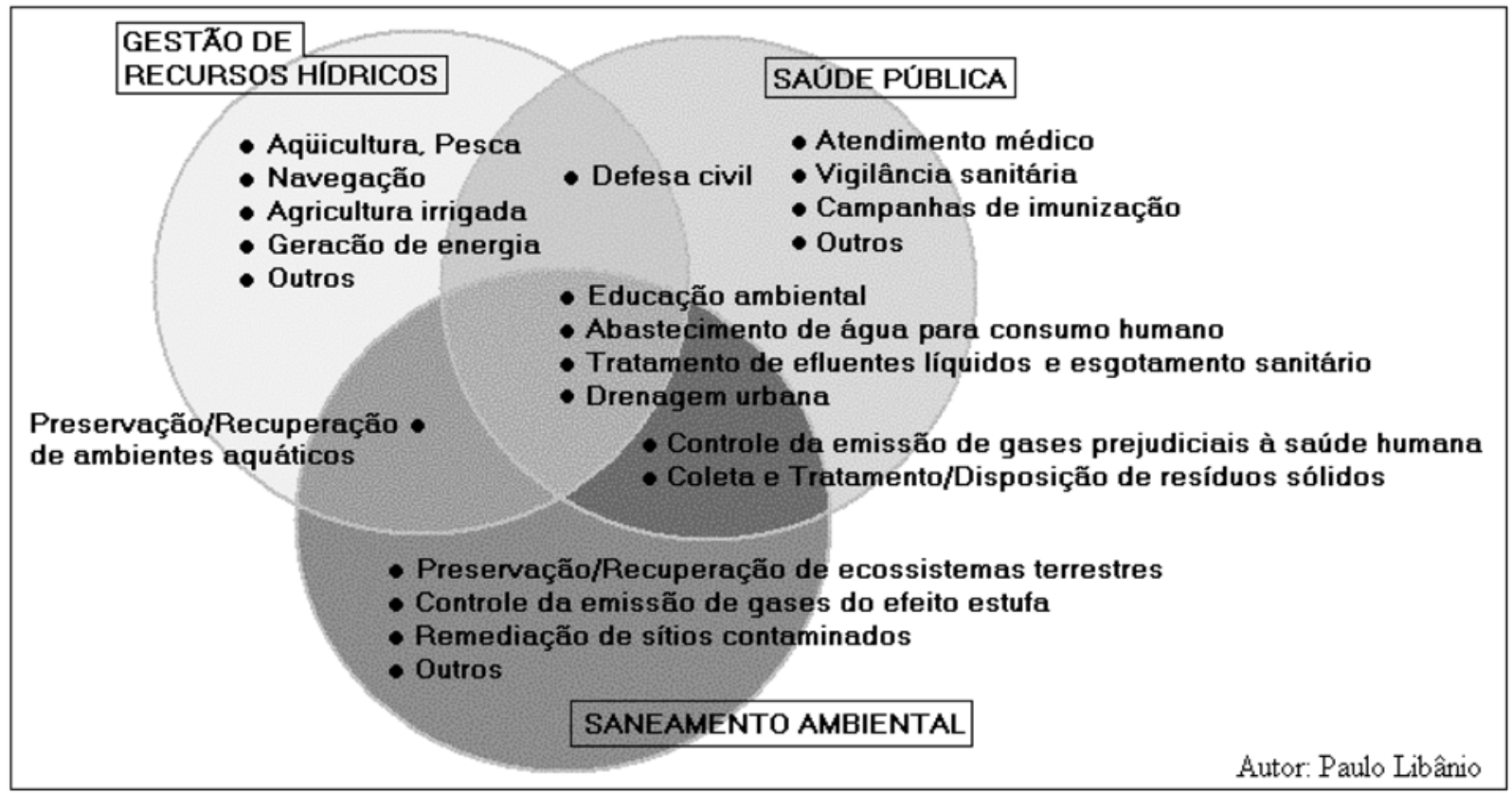

Fonte: Libânio (2004).

Figura I - Interfaces do saneamento ambiental com a gestão de recursos hídricos e com a saúde pública 
constatação levou ao desenvolvimento no âmbito do Programa das Nações Unidas para o Desenvolvimento (PNUD), no início da década de 1990, do Índice de Desenvolvimento Humano (IDH).

O IDH abrange três dimensões básicas do desenvolvimento humano longevidade, educação e renda - expressas por diferentes variáveis estatísticas: expectativa de vida ao nascer, alfabetização de adultos, matrículas combinadas nos três níveis de ensino, PIB per capita corrigido pela capacidade de compra da moeda.

Na composição do IDH, as três dimensões têm igual peso e são descritas por índices parciais que podem variar entre 0 e 1 , sendo os valores mais próximos à unidade indicativos de maior bem-estar social. Dessa forma, segundo classificação do PNUD, é possível verificar se o desenvolvimento humano em um país é baixo $(0<\mathrm{IDH}<0,5)$, médio $(0,5<\mathrm{IDH}<0,8)$ ou alto $(0,8<\mathrm{IDH}<1,0)$.

No presente trabalho, para a análise comparativa do desenvolvimento humano com outras variáveis, em nível global, utilizaram-se os valores de IDH e de expectativa de vida ao nascer em 174 países, referentes ao ano de 2000, disponíveis no Human Development Report 2002, publicado pelo Programa das Naçôes Unidas para o Desenvolvimento (UNDP, 2002).

Por sua vez, em avaliações semelhantes para os municípios e estados brasileiros, foram consultados os dados de IDH e de expectativa de vida ao nascer, constantes no Atlas do Desenvolvimento $\mathrm{Hu}$ mano no Brasil 2000 (UNDP, IPEA e FJP, 2003) e na publicação Indicadores de Desenvolvimento Sustentável no Brasil 2002 (IBGE, 2002).

As estatísticas constantes na primeira publicação correspondem aos dados dos censos de 1991 e 2000. No cálculo do IDH nos municípios (IDH-M), houve necessidade de adaptações das estatísticas - por exemplo, substituição do PIB per capita pela renda familiar per capita média do município - bem como alteração dos valores-limite de cálculo dos índices parciais.

\section{Indicadores de saúde: índice de mortalidade e morbidade}

A legislação brasileira determina que todas as mortes devem ter registro (certidão de registro de óbito), com a definição da causa mortis por atestado médico ou por testemunhas qualificadas nos termos legais (Lei $\mathrm{n}^{\circ}$ 6.015/73, art. 78), bem como outras informações pessoais (art. 81 da referida Lei). Essas informações vêm, então, a constituir as estatísticas de mortalidade, essenciais para a elaboração e análise de diversos indicadores de saúde, subsidiando o desenvolvimento de estudos epidemiológicos.

No Brasil, as estatísticas oficiais de mortalidade constituem uma ampla base de dados: o Sistema de Informações sobre Mortalidade (SIM). Esse sistema é gerido pelo Departamento de Análise de Situação de Saúde (DASIS), da Secretaria de Vigilância em Saúde (SVS/MS), em conjunto com as Secretarias Estaduais e Municipais de Saúde. Essas últimas são responsáveis pela coleta das informaçōes contidas nas declarações de óbitos dos cartórios e por repassá-las ao SIM.

Outro indicador de saúde pública investigado quanto à sua relação com as condições de saneamento básico foi o índice de morbidade. A base de dados consultada, nesse caso, foi o Sistema de Informações Hospitalares do SUS (SIH/SUS), desenvolvido pelo Ministério da Saúde, por meio de sua Secretaria de Assistência à Saúde, conjuntamente com as Secretarias Estaduais e Municipais de Saúde em todo País.

Conforme determinação da Portaria $\mathrm{MS} \mathrm{n}^{\circ} 1.832 / 94$, desde 1996 , as causas básicas de óbito são codificadas segundo a $10^{\underline{a}}$ Revisão da Classificação Internacional de Doenças (CID-10) da Organização Mundial de Saúde. Semelhantemente, os dados de morbidade disponíveis no SIH/SUS, para os períodos de 1998 em diante, estão organizados conforme disposto na Lista de Tabulação para Morbidade da CID-10.

Particularmente, nesse trabalho, interessaram os dados do ano 2000 disponibilizados, via internet, pelo DATASUS, relativos aos óbitos e às internações por algumas doenças infecciosas e parasitárias que podem ser associadas à poluição hídrica. As doenças infecciosas e parasitárias constituem o Capítulo I da CID-10, no qual estão listadas inúmeras enfermidades relacionadas à contaminação das águas por microrganismos patogênicos de origem humana (amebíase, cólera, diarréias e gastroenterites, entre outras).

Todavia, o Capítulo I da CID-10 agrega também enfermidades cuja transmissão ocorre por outros meios que não dependem das condiçôes sanitárias, por exemplo, as doenças de transmissão pre- dominantemente sexual. Dessa forma, foram selecionadas para consulta no banco de dados do DATASUS apenas as seguintes enfermidades ou grupos específicos de doenças: cólera, febres tifóide e paratifóide, amebíase, diarréia e gastroenterite de origem infecciosa presumível, outras doenças infecciosas intestinais, leptospirose, restante de outras doenças bacterianas, hepatites virais, esquistossomose, restante de doenças transmitidas por protozoários, restante de helmintíases, outras doenças infecciosas e parasitárias.

\section{Indicadores de saneamento básico: cobertura por serviços de água e esgoto}

Os indicadores de saneamento básico investigados no presente trabalho restringiram-se àqueles relativos ao atendimento das populações por sistemas de abastecimento de água e de esgotamento sanitário.

$\mathrm{Na}$ avaliação da situação em escala mundial, utilizaram-se os dados divulgados no Relatório Global Water Supply and Sanitation Assessment 2000 (WHO/UNICEF, 2000), produto de um programa global de monitoramento do setor de saneamento. A pesquisa abrangeu países distribuídos em 6 grandes regiões do Planeta, sendo implementada pelas representações regionais da OMS e UNICEF, instituiçôes co-responsáveis pelo programa, com apoio de agências nacionais, por meio da aplicação de questionários e pesquisa em domicílios.

$\mathrm{Na}$ estimativa dos índices de atendimento nos diversos países, foram consideradas somente as técnicas de suprimento de água e de esgotamento sanitário definidas como "aprimoradas", tais como fornecimento de água e coleta de esgotos por rede geral.

A situação brasileira, por sua vez, foi percebida quanto ao atendimento domiciliar por rede de água e de esgoto, dados disponíveis no Censo demográfico 2000 (IBGE, 2000). Dessa forma, enquanto as estatísticas por estado corresponderam aos valores percentuais de moradores em domicílios particulares permanentes atendidos por rede de água e esgoto em relação à população total, conforme apresentado em Indicadores de Desenvolvimento Sustentável no Brasil 2002 (IBGE, 2002), no nível municipal, inferiu-se o nível de cobertura dos serviços de água e esgoto pela razão entre os domicílios 
conectados às redes de abastecimento de água e de esgotamento sanitário e o número total domicílios particulares permanentes.

Não foram computados, assim, outros tipos de abastecimento de água e de esgotamento sanitário investigados no Censo demográfico 2000, tais como abastecimento de água por poços e os sistemas de fossa séptica, o que contribuiria para uma percepção mais favorável quanto ao quadro sanitário no País. A opção de desconsiderá-los justifica-se pela limitação da referida pesquisa censitária em averiguar a confiabilidade desses sistemas, sendo amplamente conhecidos os problemas quanto à contaminação das águas dos poços e à construção e manutenção das fossas sépticas.

Por outro lado, ignoraram-se deficiências recorrentes dos serviços de abastecimento por rede de água, tais como a qualidade da água distribuída à população e a intermitência no seu fornecimento, informações não disponíveis no estudo consultado. Ademais, pela metodologia adotada na pesquisa censitária do IBGE, não é possível discriminar as ligaçôes indevidas na rede de drenagem pluvial, declaradas como ligaçóes à rede de esgotamento sanitário.

\section{Potencial e disponibilidade hídrica}

Os dados relativos à potencialidade hídrica, em escala global, constam do relatório Review of World Water Resources by Country (FAO, 2003), produto do programa Aquastat, um sistema global de informaçōes sobre recursos hídricos e agricultura que abrange 170 países e territórios. Cabe ressaltar que o referido relatório limitou-se à avaliação quantitativa das reservas renováveis de água doce, em termos das médias anuais de vazóes em cursos d'água e recarga de aqüíferos.

$\mathrm{Na}$ avaliação da disponibilidade hídrica no território nacional, utilizou-se as informaçōes constantes da mesma base de dados das regiōes hidrográficas brasileiras, atualizada e organizada pela Agência Nacional de Águas, que subsidiou a elaboração do Documento Base para Discussão do Plano Nacional de Recursos Hídricos (ANA/SRH/MMA, 2002). Os valores de disponibilidade hídrica per capita consultados na referida base de dados, resultam da razão entre as vazões médias de longo período em cada unidade hidrográfica de referência - determinadas pelas séries hidrológicas dos regis- tros de vazão em estações fluviométricas, disponíveis no Sistema de Informações Hidrológicas da ANA (Sistema HIDRO) - e as respectivas populaçôes aferidas no Censo 2000 (IBGE, 2000).

\section{RESULTADOS E DISCUSSÃO}

\section{A disponibilidade hídrica e os indicadores sociais}

É conhecido o fato de que países com grande potencial hídrico, caso do Brasil que responde por cerca de $16 \%$ da recarga hídrica anual sobre os continentes, não detêm, simplesmente por essa condição, maiores oportunidades para o desenvolvimento econômico e para a prosperidade social.

Algumas das grandes economias mundiais, especialmente os países da Europa e o Japão, usualmente apropriam-se de um volume de recursos bem superior a suas próprias dotaçôes naturais (Cairncross, 1993). No caso específico dos recursos hídricos, o volume de produtos comercializados em transações internacionais, ou mesmo entre diferentes regiōes de um mesmo país, tem importantes implicaçôes na avaliação das disponibilidades hídricas (Allan, 2003).

Isso porque para cada bem produzido, faz-se necessário dispor de um certo volume de água, seja para incorporá-lo ao próprio produto, seja para diluir os rejeitos da sua produção. Assim, a importação de mercadorias ou commodities com elevada demanda hídrica específica acaba por contribuir, indubitavelmente, para a redução do déficit hídrico nos países importadores, uma vez que um volume de água equivalente deixa de ser suprido localmente e torna-se disponível para outras necessidades (Hoekstra, 2003).

Nesse sentido, a opção por importar determinados produtos ao invés de produzi-los localmente não é somente uma decisão de política econômica, configurando-se também como uma alternativa para gestão de recursos hídricos (Hoekstra, 2003). Allan (2003) advoga que, em algumas situações, a solução do déficit hídrico via comércio internacional pode ser mais vantajosa e adequada que as soluçôes de engenharia, usualmente adotadas.

Hoekstra \& Hung (2002) concluíram em seu relatório que, no período de 1995 a 1999, aproximadamente $695 \mathrm{~km}^{3} /$ ano de água ou $13 \%$ da demanda hídrica anual global para agricultura - equivalente a $5400 \mathrm{~km}^{3} / \mathrm{ano}$, incluindose o volume irrigado e naturalmente disponível - não corresponderam às demandas para consumo doméstico de produtos agrícolas, mas sim, ao suprimento de mercados externos. Segundo os mesmos autores, os produtos da pecuária e industriais transacionados no comércio internacional corresponderam, no mesmo período, à transferência de volumes de água virtual da ordem de 245 e $100 \mathrm{~km}^{3} /$ ano, respectivamente.

Dessa forma, a simples razão $r$ curso/população não pode ser considerada o único fator limitante ou representativo do desenvolvimento humano, devendo ser consideradas outras variáveis explicativas. O gráfico da Figura 2 apresenta a baixa correlação entre o Índice de Desenvolvimento Humano (IDH) e a reserva hídrica superficial per capita, medida em termos da recarga hídrica anual, para diversos países agrupados segundo classificação apresentada em Rebouças (2002).

No Brasil, a baixa correlação entre a disponibilidade hídrica per capita e o desenvolvimento humano também fica patente quando observadas a distribuição geográfica dessas variáveis no território nacional (Figura 3).

Não há dúvidas de que a indisponibilidade de água em quantidade suficiente para atendimento das demandas estabelecidas ou potenciais constitui-se em um fator crítico para o desenvolvimento de algumas regiões do país - norte de Minas Gerais e região Nordeste - nas quais é possível notar alguma correlação entre essas variáveis (Figura 3).

Todavia, verifica-se também, nos mapas apresentados na Figura 3, regiōes com menor disponibilidade hídrica per capita $\left(<10.000 \mathrm{~m}^{3} /\right.$ hab.ano $)$ - noroeste do Paraná, e na maior parte dos estados de São Paulo e Rio de Janeiro - mas com IDH mais elevado (IDH > 0,7); havendo outras com maior disponibilidade de água (> $100.000 \mathrm{~m}^{3} /$ hab.ano) - estados do Acre e Amazonas - e menor IDH $(\mathrm{IDH}<0,7)$.

Portanto, a disponibilidade hídrica não deve ser a única variável explicativa do desenvolvimento regional no País. As reservas hídricas, se medidas exclusivamente em termos quantitativos, não dizem muito quanto à disponibilidade, mas somente, quanto à potencialidade. $\mathrm{O}$ primeiro conceito diferencia-se do último por ser sensível às pressóes antrópicas sobre o sistema natural, as quais impõe a consideração conjunta de requisitos de quantidade e de qualidade de água. 


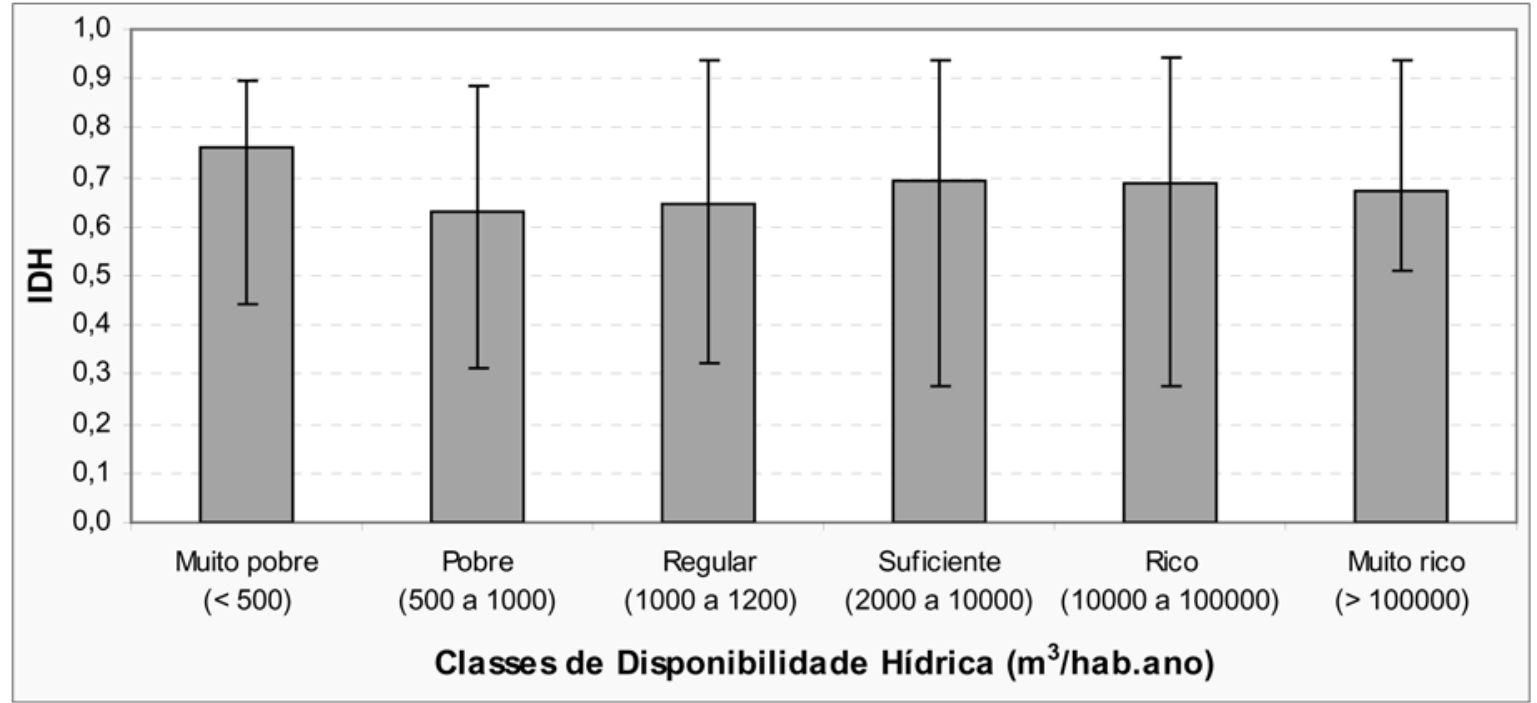

Fontes: FAO (2003), UNDP (2002).

Figura 2 - Índice de Desenvolvimento Humano (IDH) em 165 países agrupados segundo classes de disponibilidade hídrica. Valores médios, mínimos e máximos

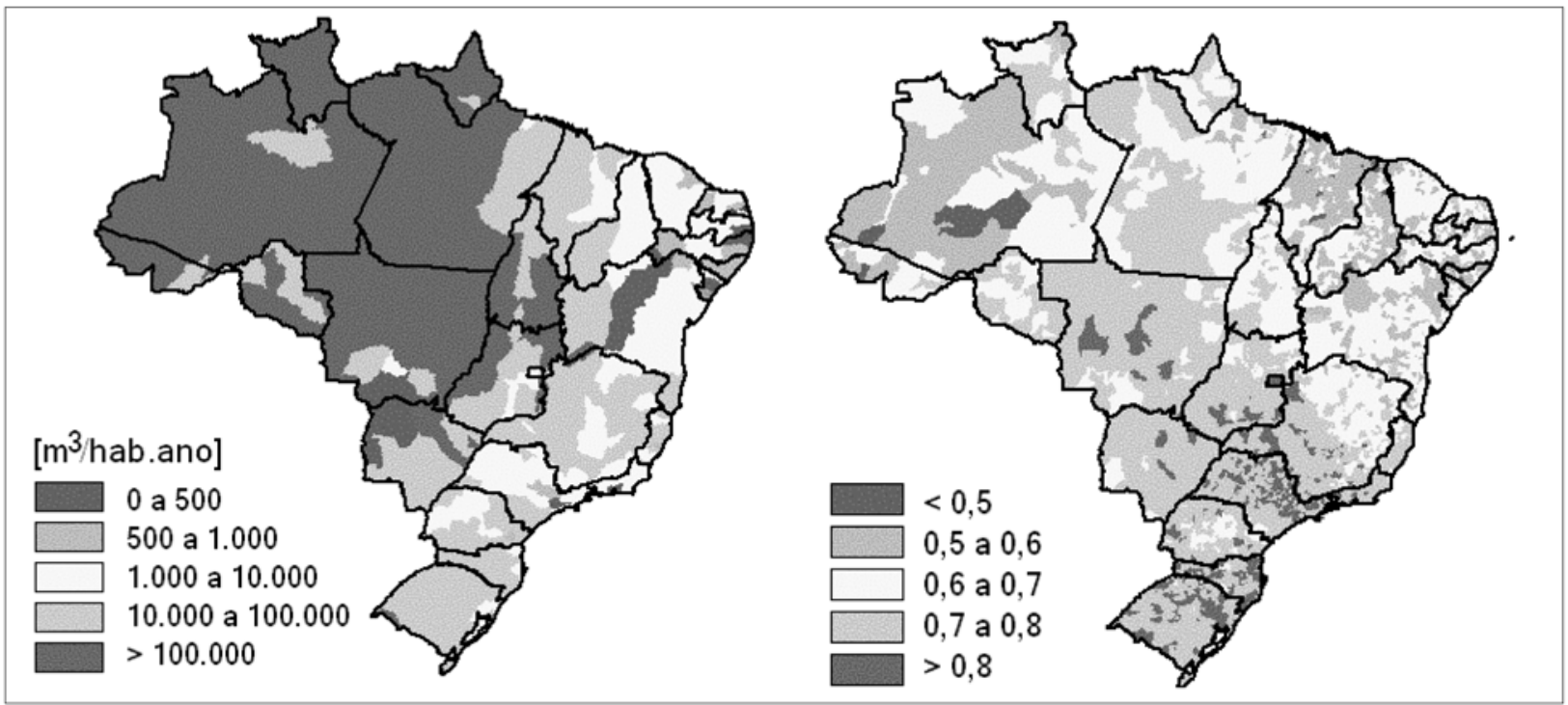

Fontes: UNDP, IPEA e FJP (2000) e ANA, SRH e MMA (2002).

Figura 3 - Avaliação conjunta da disponibilidade hídrica per capita e do índice de desenvolvimento humano no Brasil

\section{Os serviços de saneamento e os indicadores sociais}

A existência ou não de ações de saneamento ambiental, exercidas em caráter preventivo ou remediador, bem como a forma e adequação de sua prática à realidade social e econômica, acabam por dizer muito mais a respeito do desenvolvimento humano que a própria potencialidade do meio natural (Figura 4).
A clara correlação entre o Índice de Desenvolvimento Humano (IDH) e a abran- gência dos serviços de saneamento básico nesse conjunto de países pode ser explicada pelo fato de o cálculo desse índice levar em consideração, além de estatísticas de renda e de educação da população, a expectativa de vida ao nascer. Essa última é um importante indicador de saúde e retrata, em certo grau, as condições de saneamento, conforme pode ser verificado nos gráficos da Figura 5.
Outra análise dos mesmos dados, por meio do mapeamento desses indicadores sociais e de saúde - IDH e expectativa de vida - segundo as estatísticas sobre as condições de saneamento - atendimento por sistemas de abastecimento de água e esgotamento sanitário - também permite constatar a relação saneamento-desenvolvimento humano (Figura 6). 

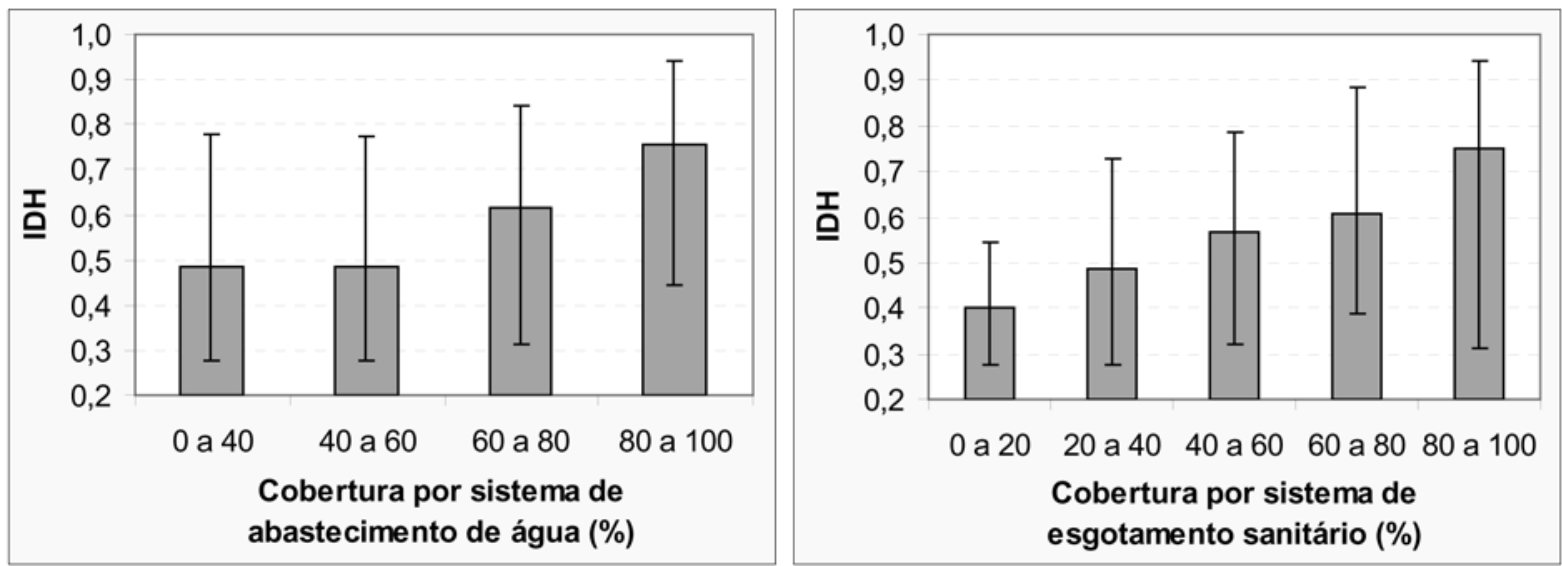

Fontes: UNDP (2002) e WHO e UNICEF (2000).

Figura 4 - Índice de Desenvolvimento Humano em I 27 países, agrupados segundo os níveis de atendimento por sistemas de água e esgotos. Valores médios, mínimos e máximos
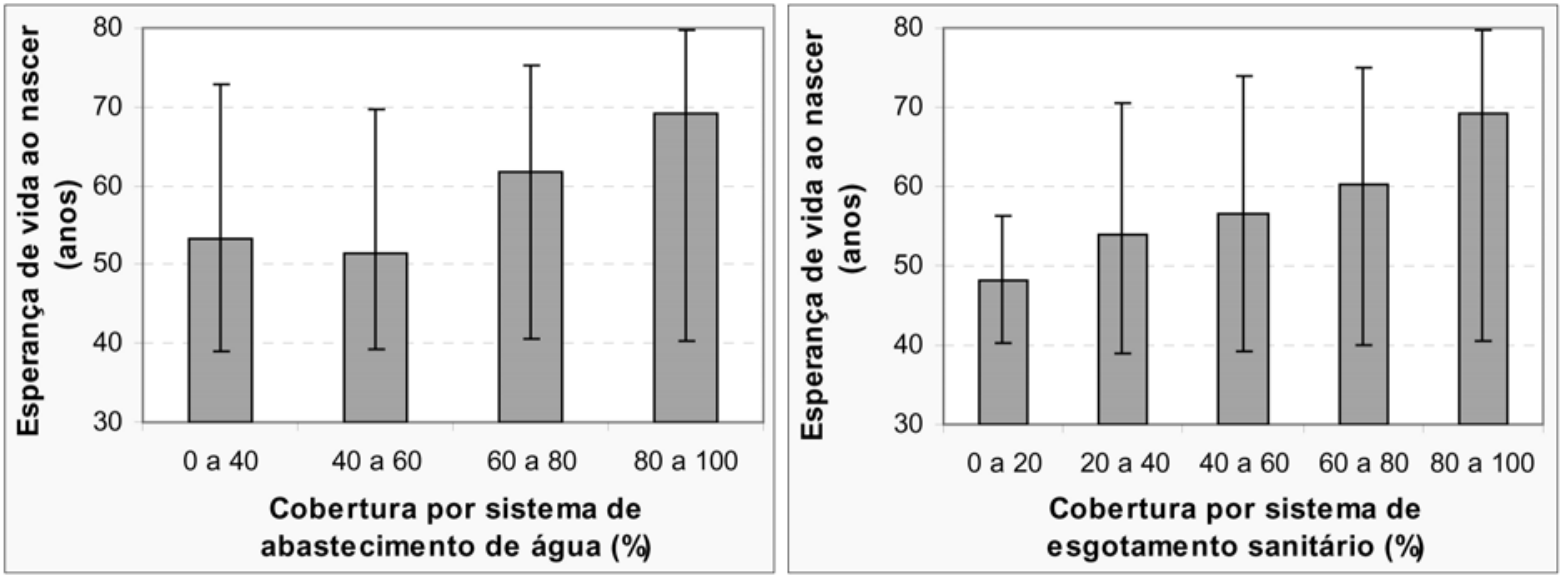

Fontes: UNDP (2002) e WHO e UNICEF (2000).

Figura 5 - Esperança de vida ao nascer em 127 países agrupados segundo os níveis de atendimento por sistemas de água e esgotos. Valores médios, mínimos e máximos
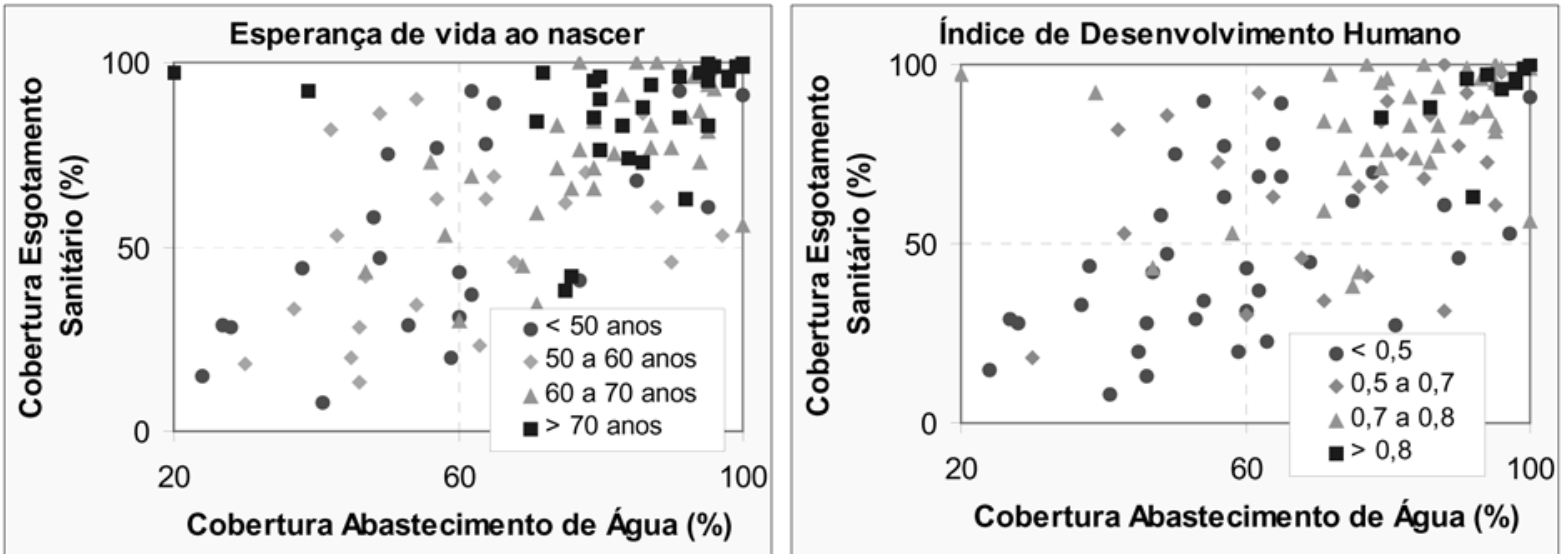

Fontes: UNDP (2002) e WHO e UNICEF (2000).

Figura 6 - Avaliação da correlação entre estatísticas sobre as condições sociais e parâmetros indicativos da situação de saneamento básico em I 27 países 
Em sua grande maioria, os países que apresentam IDH mais elevado (IDH > 0,7) e maior longevidade (esperança de vida ao nascer $>60$ anos) situam-se no quadrante de maior cobertura dos serviços de saneamento (cobertura de água $>60 \%$ e cobertura de esgoto $>50 \%$ ). Por sua vez, os pontos correspondentes aos países com menor IDH (IDH $<0,7)$ e longevidade (esperança de vida ao nascer $<60$ anos) encontram-se mais dispersos no mapa, ocupando em grande número os quadrantes equivalentes a uma pior situação sanitária (cobertura de água $<60 \%$ e cobertura de esgoto $<50 \%$ ).
A análise conjunta de indicadores sociais e de saneamento, no Brasil, inicialmente no nível dos estados, confirma a inter-relação entre os mesmos e as condições sanitárias prevalecentes (Figura 7).

Verifica-se que os estados com piores indicadores sociais - menor esperança de vida (60 a 65 anos) e IDH $(<0,6)$ apresentam menores índices de cobertura por rede de esgotamento sanitário $(<50 \%)$ enquanto aqueles com melhores indicadores sociais - maior esperança de vida (> 70 anos) e IDH $(>0,7)-$ apresentam maiores índices de cobertura por rede de abastecimento de água (> 60\%).
Os indicadores sociais e de saneamento, se investigados nos municípios brasileiros, também apontam no mesmo sentido, reforçando a hipótese já defendida, qual seja: as ações de saneamento são necessárias para o estabelecimento de condiçōes salubres, que permitem o pleno desenvolvimento humano (Figuras 8 a 10).

\section{Os serviços de} saneamento e os indicadores de saúde

Diversos estudos indicam uma estreita relação entre saneamento e saúde
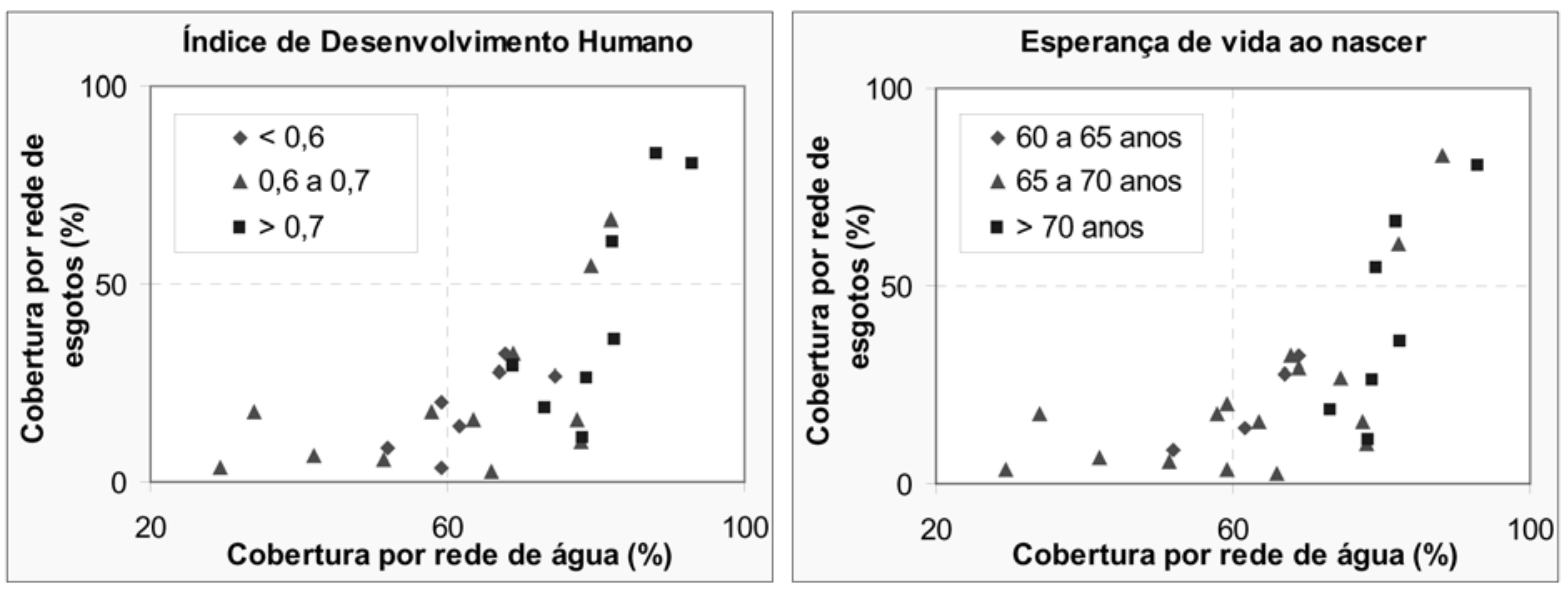

Fontes: IBGE (2002) e UNDP, IPEA e FJP (2000).

Figura 7 - Avaliação da correlação entre estatísticas sobre as condições sociais e parâmetros indicativos da situação de saneamento básico nos 26 Estados brasileiros e no Distrito Federal.
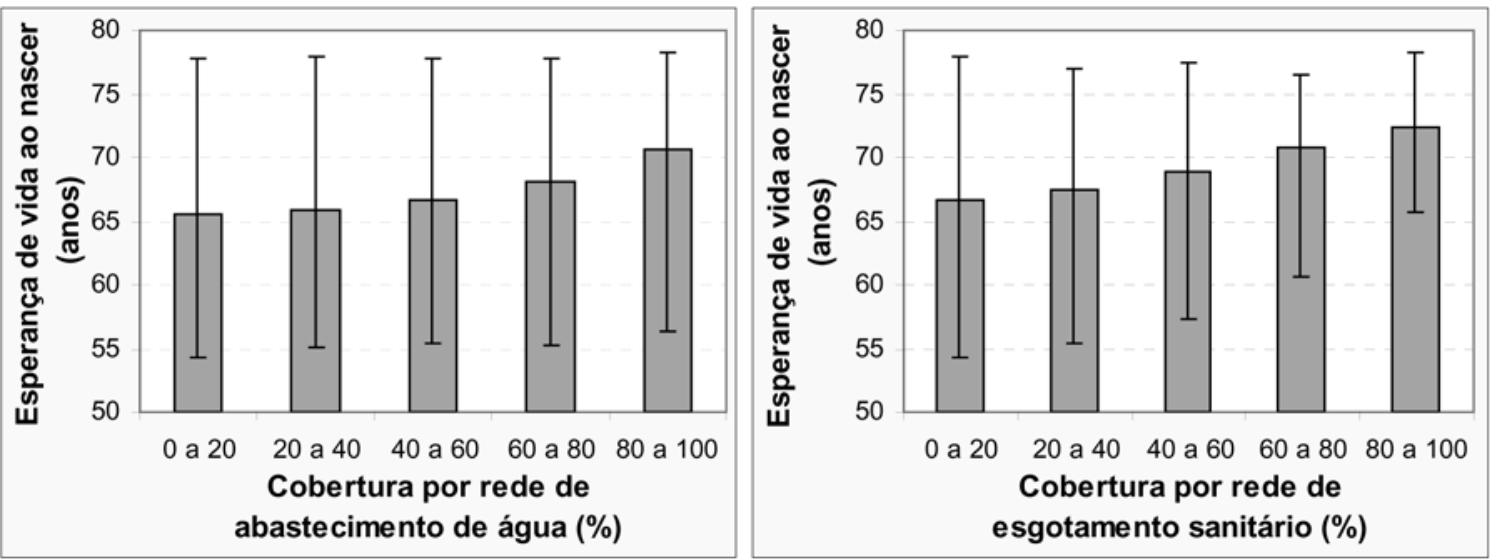

Fontes: UNDP, IPEA e FJP (2000) e IBGE (2000).

Figura 8 - Esperança de vida ao nascer nos municípios brasileiros, agrupados segundo os níveis de atendimento à população por redes de água e esgoto. Valores médios, mínimos e máximos 

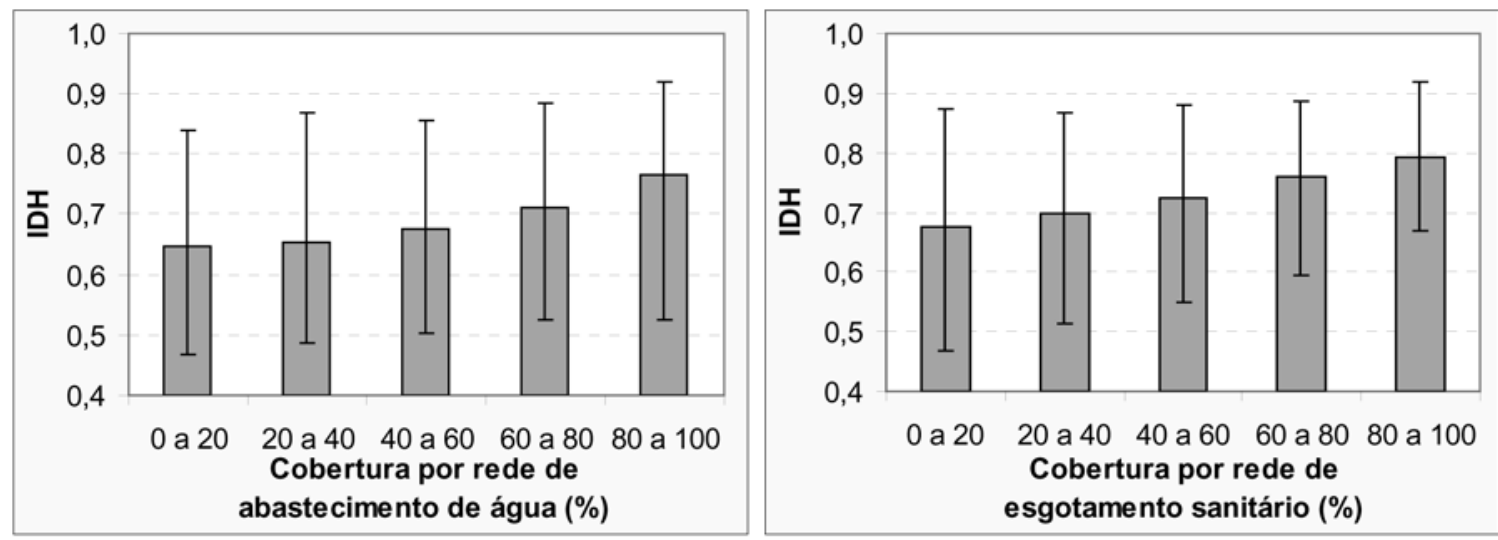

Fontes: UNDP, IPEA e FJP (2000) e IBGE (2000).

Figura 9 - Índice de Desenvolvimento Humano (IDH) nos municípios brasileiros, agrupados segundo os níveis de atendimento à população por redes de água e esgoto. Valores médios, mínimos e máximos
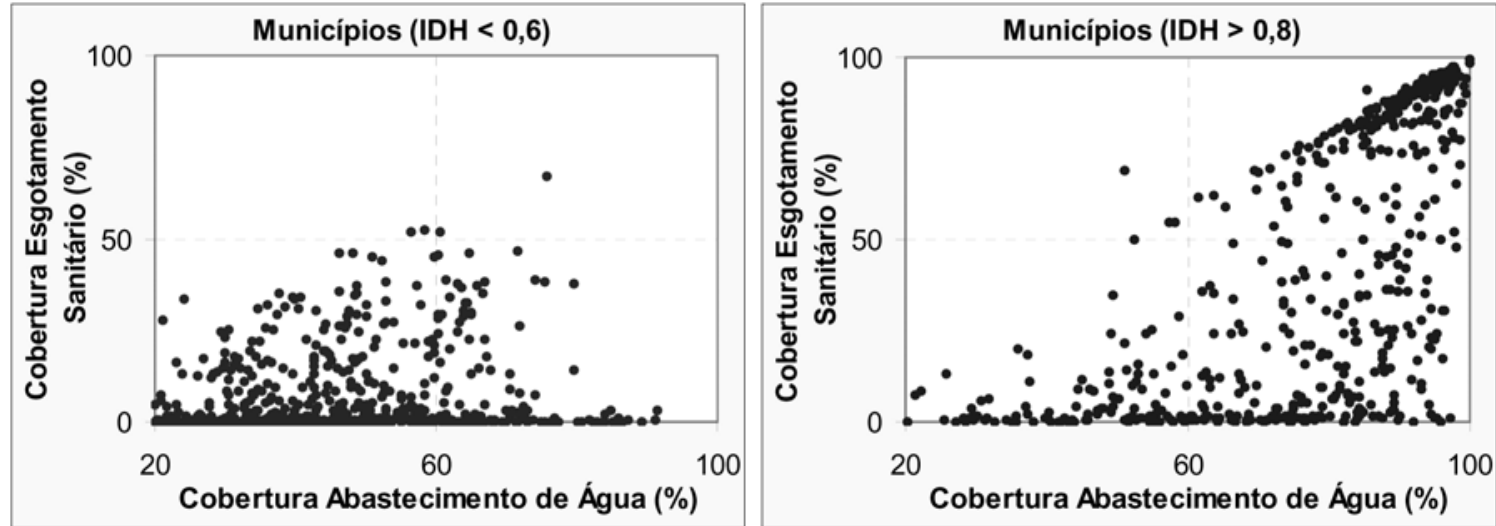

Fontes: UNDP, IPEA e FJP (2000) e IBGE (2000).

\section{Figura I 0 - Avaliação da correlação entre parâmetros indicativos da situação de saneamento básico e o Indice de Desenvolvimento Humano (IDH) nos municípios brasileiros}

pública. Heller (1997) fez uma vasta revisão da literatura então disponível, focando a relação entre saneamento e saúde, e concluiu que os estudos já realizados permitem atestar a melhoria dos indicadores de saúde pública em função de intervençōes em abastecimento de água e esgotamento sanitário.

No Brasil, as péssimas condições sanitárias verificadas em muitas das bacias hidrográficas densamente e desordenadamente ocupadas, resultam na degradação generalizada dos elementos naturais e, obviamente, dos recursos hídricos. É realidade comum o lançamento de esgotos sanitários não tratados, a disposição inadequada de resíduos sólidos nas mediaçôes de cursos d'água ou em locais sem infra-estrutura adequada, loteamentos clandestinos e outras. A Figura 11 registra a baixa cobertura dos serviços de esgotamento sanitário na grande maioria dos estados brasileiros e seus efeitos sobre os indicadores de saúde pública.
Interessante notar que os estados com piores indicadores de saúde - maior taxa de mortalidade $(>0,07 \%$ ) e de morbidade $(>6 \%$ ) - apresentam menores índices de cobertura por rede de esgotamento sanitário (<50\%) mas não, necessariamente, menores índices de cobertura por rede de água (<60\%). Por sua vez, os estados com os melhores indicadores de saúde - menores taxas de mortalidade $(<0,04 \%$ ) e morbidade $(<3 \%$ ) - situam-se entre aqueles que apresentam os maiores índices de cobertura por rede de abastecimento de água (>60\%).

A correlação entre os indicadores de saúde e a cobertura por serviços de água e esgoto pode ser também facilmente visualizada na avaliação do universo dos municípios brasileiros (Figura 12).

\section{CONCLUSÕES}

Deve-se reconhecer que existem diversos outros fatores determinantes para a distribuição demográfica e para o desenvolvimento das sociedades - históricos, culturais, políticos, econômicos, tecnológicos e outros - que independem do potencial hídrico.

Particularmente, nesse artigo, a análise conjunta das informações contidas nos diferentes estudos consultados demonstrou que o bem-estar das populaçôes apreendido pelos indicadores sociais e de saúde - nos diversos países e no território nacional é melhor retratado pela abrangência dos serviços de água e de esgotamento sanitário, do que propriamente pelo potencial hídrico ou pela disponibilidade de água per capita.

Tal constatação evidencia a importância da discussão das interfaces da gestão de recursos hídricos com setores dependentes de água de boa qualidade, em especial, com o setor de saneamento, sob cuja responsabilidade encontram-se os serviços de água e de esgotos indispensáveis à promoção da saúde pública. 

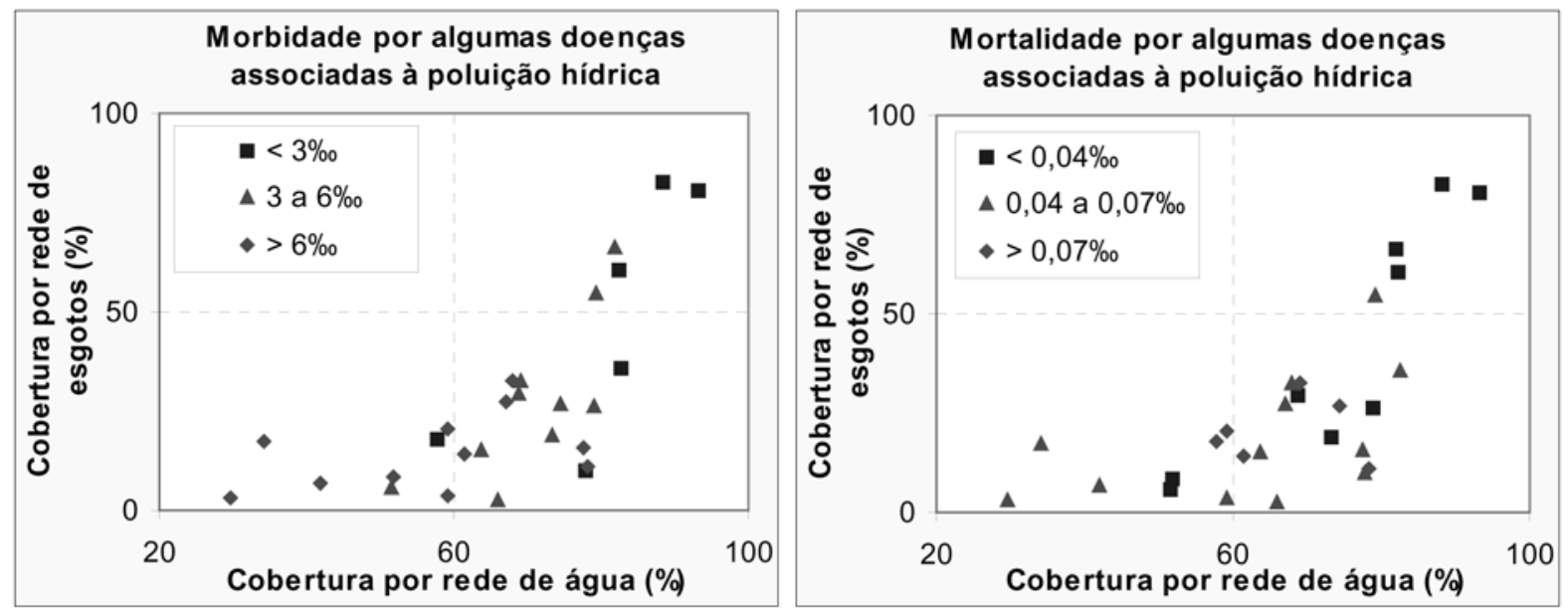

Fontes: IBGE (2002), SIM (2000) e SIH/SUS (2000).

Figura II - Avaliação da correlação entre os índices de mortalidade e morbidade por doenças associadas à poluição hídrica e parâmetros indicativos da situação de saneamento básico nos 26 estados brasileiros e no Distrito Federal
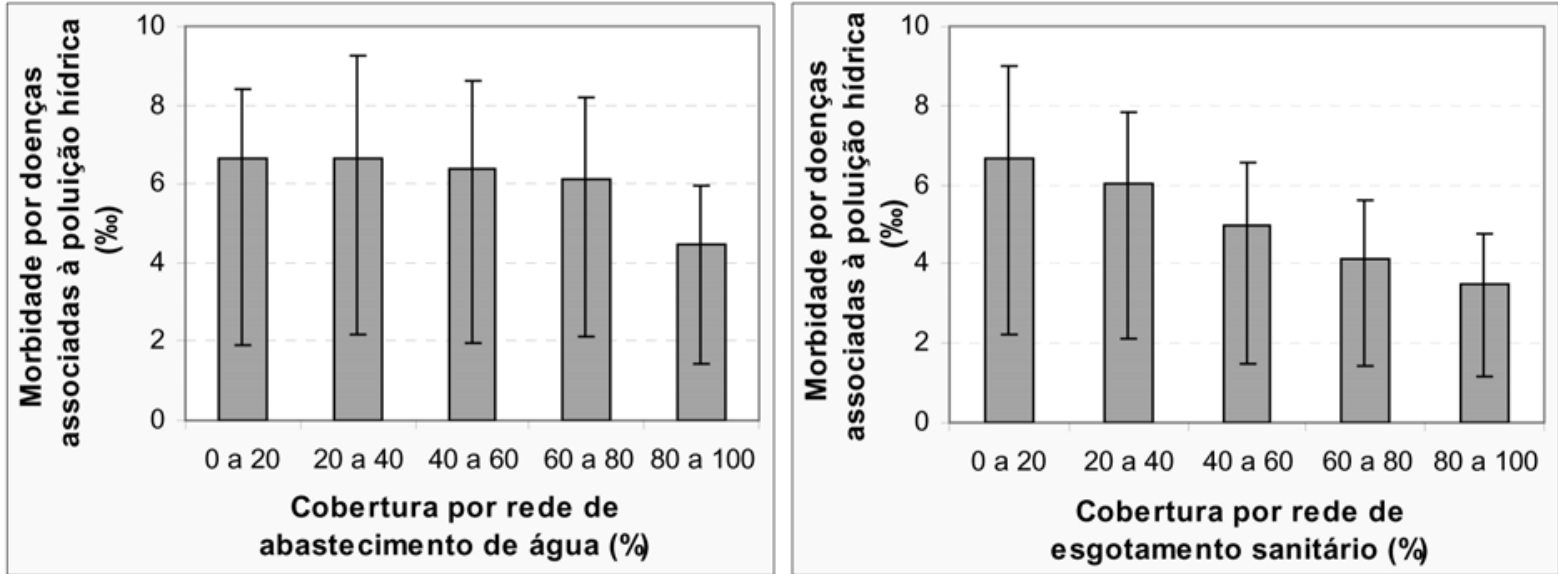

Fontes: SIH/SUS (2000) e IBGE (2000).

Figura I 2 - Avaliação da correlação entre indicadores de saneamento básico e os índices de morbidade por doenças associadas à poluição hídrica, nos municípios brasileiros. Valores médios e amplitude interquartil

Nesse sentido, o sistema de gestão de águas a ser implementado no país somente garantirá o aproveitamento sustentável desse recurso se for estabelecida uma nova dinâmica para o planejamento e para a realização de ações de saneamento - ou de proteção ambiental, em caráter mais amplo-de forma integral e coordenada, em escala coincidente com a de atuação dos órgãos gestores de recursos hídricos, ou seja, as bacias hidrográficas.

\section{REFERÊNCIAS}

ALLAN, J. A. Virtual Water - the Water, Food, and Trade Nexus. Useful Concept or Misleading Metaphor. International Water Resources Association. Water International, v.28, n.1, p. 106-113, mar. 2003.
ANA; SRH; MMA. Documento Base de Discussão do Plano Nacional de Recursos Hidricos. Dezembro de 2002. Disponível em: <http:// pnrh.cnrh-srh.gov.br>. Acesso em: 12 nov. 2003.

BRASIL. Lei no 6.015 , de 31 de dezembro 1973. Dispõe sobre os registros públicos, e dá outras providências.

BRASIL. Lei no 8.080, de 19 de setembro de 1990. Dispõe sobre as condiçōes para a promoção, proteção e recuperação da saúde, a organização e o funcionamento dos serviços correspondentes e dá outras providências.

BRASIL. Lei no 9.433, de 8 de janeiro de 1997. Institui a Política Nacional de Recursos Hídricos, cria o Sistema Nacional de Gerenciamento de Recursos Hídricos, regulamenta o inciso XIX do art. 21 da Constituição Federal, e altera $o$ art. $1^{\circ}$ da Lei ${ }^{\circ} 8.001$, de 13 de março de 1990 , que modificou a Lei $\mathrm{n}^{\circ}$ 7.990 , de 28 de dezembro de 1989.
CAIRNCROSS, F. Costing the Earth: The Challenge for Governments, The Opportunities for Business. Boston: Harvard Business School Press, 341p. 1993.

FAO - Food and Agriculture Organization of the United Nations. Review of World Water Resources by Country. Rome: FAO's Aquastat Programme, (Water Reports 23). 2003.

HELLER, L. Saneamento e Saúde. Brasília: OPAS/OMS - Representação do Brasil, 1997.

HOEKSTRA, A. Y. Virtual Water Trade: Proceedings of the International Expert Meeting on Virtual Water Trade. The Netherlands: IHE Delft, (Value of Water Research Report Series, Number 12). 2003.

HOEKSTRA, A. Y.; HUNG, P. Q. Virtual Water Trade: A Quantification of Virtual Water Flows Between Nations in Relation to International Crop Trade. The Netherlands: IHE Delft, (Value of Water Research Report Series, Number 11). 2002. 
IBGE - Instituto Brasileiro de Geografia e Estatísticas. Indicadores de Desenvolvimento Sustentável: Brasil 2002. Rio de Janeiro: Diretoria de Geociências, (Estudos e Pesquisas, Informação Geográfica, n.2), 195p. 2002.

IBGE - Instituto Brasileiro de Geografia e Estatísticas. Censo Demográfico 2000. Caracteristicas da população e dos domicílios - Resultados do universo. Rio de Janeiro, 520p. 2000.

LIBÂNIO, P. A. C. A Implementação da Política Nacional de Recursos Hidricos e sua Interface com Aspectos de Qualidade de Água: Implicações da Regulação de Recursos Hidricos sobre o Setor de Saneamento e no Controle da Poluição Hídrica. Versão preliminar da tese de doutorado apresentada para Exame de Qualificação. Belo Horizonte: Programa de Pós-Graduação em Saneamento, Meio Ambiente e Recursos Hídricos da UFMG, 2004.

MUÑOZ, H. R. Razões para um debate sobre as interfaces da gestão dos recursos hidricos no contexto da Lei de Águas de 1997. In: MUÑOZ H. R. (Coord.) Interfaces da Gestão de Recursos Hídricos: Desafios da Lei de Águas em 1997. 2. ed. Brasília: Secretaria de Recursos Hídricos do Ministério do Meio Ambiente. p.13-30. 2000.
REBOUÇAS, A. C. Água Doce no Mundo e no Brasil. In: REBOUÇAS, A. C.; BRAGA, B.; TUNDISI, J. G. (Org.) Águas Doces no Brasil: Capital Ecológico, Uso e Conservação. 2. ed. São Paulo, Escrituras Editora, 703p. 2002.

SIH/SUS - Sistema de Informações Hospitalares do SUS. Morbidade Hospitalar do SUS por local de residência. Tabulação em âmbito nacional, Período de 2000. Disponível em: <http:/ /tabnet.datasus.gov.br/cgi/sih/mrmap.htm>. Acesso em: 03 mai. 2004.

SIM - Sistema de Informações sobre Mortalidade. Tabulação em âmbito nacional, Período 2000. Disponível em: <http:// tabnet.datasus.gov.br/cgi/sim/obtmap.htm >. Acesso em: 03 mai. 2004.

UNDP - United Nations Development Programme. Human Development Report 2002: Deepening Democracy in a Fragmented World. New York: Oxford University Press, 2002.

UNDP - United Nations Development Programme. Human Development Report 2004: Cultural Liberty in Today's Diverse World. New York, 2004.
UNDP; IPEA; FJP. Atlas do Desenvolvimento Humano no Brasil. Banco de dados eletrônico, 2003. Disponível em: <http:// www.pnud.org.br>. Acesso em: 10 jan. 2004.

WHO; UNICEF. Global Water Supply and Sanitation Assessment 2000 Report. New York: WHO, UNICEF Joint Monitoring Programme for Water Supply and Sanitation, 2000.

\section{Endereço para correspondência:}

Paulo Augusto Cunha Libânio Agência Nacional de Águas - ANA

Setor Policial, Área 5, Quadra 3,

Bloco B, Sala 207

706 I 0-200 Brasília - DF - Brasil

Tel.: (6I) 2 I09-5 I62

E-mail: plibanio@aol.com 